\title{
Economic evaluation of innovative technologies in health care should include a short-run perspective
}

\author{
Eddy M. M. Adang
}

Received: 3 January 2007/ Accepted: 18 December 2007 / Published online: 10 January 2008

(C) The Author(s) 2008

\begin{abstract}
Knowledge about the cost-effectiveness of innovative technologies or new guidelines in health care is more and more a necessary condition for implementation in common practice. However, there are situations where implementation of a new technology that is found more effective and cost effective and is strongly advocated by the medical profession stagnates. The reason for this is the discrepancy between long-run efficiency, on which cost effectiveness is based, and short-run efficiency. This paper addresses the potential paradox between long-run and short-run efficiency in health care and explores possibilities to overcome hurdles to implementation due to that paradox.
\end{abstract}

Keywords Short-run efficiency · Long-run efficiency · Cost-effectiveness analysis - Diseconomies of scale .

Scope and learning

\section{Introduction}

In the Netherlands, as in other European countries and the US, there is consensus that evidence surrounding new technologies nowadays should include cost-effectiveness information. Technology is generally broadly conceived, covering specific medical technologies, integrated care modalities, clinical practice guidelines, etc. If the evidence of new technologies is convincing, implementation might follow. Implementation strategies in general target

\section{E. M. M. Adang ( $\square)$}

Department of Epidemiology, Biostatistics, and HTA, Radboud University Nijmegen Medical Center, HP138, P.O. Box 9101, 6500 HB Nijmegen, The Netherlands e-mail: e.adang@mta.umcn.nl increasing speed and level of adoption of new technologies. Usually these strategies are directed to the medical profession (education, training, etc.). However, despite convincing cost-effectiveness evidence and a high willingness to implement by the medical profession, implementation might result in unanticipated losses or diseconomies in the short run, which could be important barriers to implement a technology for certain stakeholders.

Aletras [1] concludes from his empirical work on estimating long-run and short-run cost functions in a sample of Greek NHS general hospitals that the use of long-run cost functions should be avoided since it might seriously mislead policymakers. Consequently, according to Aletras, evidence on economies should presumably place lower validity weight on estimates derived from long-run as opposed to short-run cost functions.

Not only the time frame is important with regard to short- and long-run cost functions, but also the scale at which health care programs operate. In the long run it is very well possible that a technology shows constant returns to scale; however, the same technology will exhibit decreasing returns to scale in the short run. Elbasha and Messonnier [2] argue that technologies that are administered in health care settings often violate the assumption of constant returns to scale (costs increase linear with increasing production) that underlies cost-effectiveness analysis (CEA). These authors refer to various publications that illustrate the violation of the constant returns to scale assumption. For example, studies about nursing homes have revealed a mixture of findings, ranging from economies to diseconomies of scale [3-6]. In fact, violation of the constant returns to scale assumption seems extremely prevalent in health care. The constant returns to scale assumption is only appropriate when all health care 
programs or technologies are operating at an optimal scale. Imperfect competition, budgetary constraints, technology shifts, contracts, etc., may cause a health care program to be not operating at optimal scale [7, 8]. However, Kass [6] presents empirical findings that show that economies of scale were not substantial in home health care. In this setting, according to Kass [6], the ratio fixed to total costs was $5.6 \%$, as labor (about 95\%) could be considered variable costs and therefore moved linearly with output. On the other hand, Roberts et al. [8] found that about $84 \%$ of hospital costs were fixed. Another study about a new combined outpatient and home treatment of psoriasis technology showed that $89 \%$ of the anticipated savings, based on the outcomes of an earlier CEA, could not be achieved in the short run when implementing this technology due to fixed factors of production (labor and infrastructure) [7, 9].

In general, stakeholders such as the government and the medical profession, who are aware of the technology's long-run superiority, are often very disappointed if implementation stagnates, especially if the favorable costeffectiveness ratio is due to improved effects rather than to reduced costs.

Cost-effectiveness analyses (CEAs) do not provide all economic information necessary for decision making about the implementation of a new technology. There seems to be a discrepancy in the information considered sufficient for decision making about the implementation of a new costeffective technology between government, on the one hand, and for health care management on the other.

\section{Cost-effectiveness analysis neglects short-run efficiency}

The evaluation of costs and benefits of new technologies and implementation of technologies is generally discussed in the context of welfare economics where welfare losses on the short run are considered 'sunk' [10-12]. This might be true for governments given they decide on a long enough planning horizon. In this context, technologies implemented by health care providers are assumed to be infinitely divisible, and production factors are supposed to be homogeneous and consequently perfectly substitutable. However, this is usually not the case in the short run. For example, implementation of an automated expert system making a certain number of personnel obsolete is not able to collect these savings on the short run because of the fixed production factor labor (depending on the inflexibility of the underlying labor contracts), nor can a diagnostic device such as a magnetic resonance imaging device (MRI) be infinitely increased proportionately to produce efficiently at a higher scale. CEAs in general assume away the fixed factor problems.
This long-run/short-run efficiency paradox is extensively dealt with in economic theory and investment practice (see for example [12, 13]). In economic literature, it is recognized that interests of different stakeholders might conflict, which may lead to investment decisions that do not maximize shareholder wealth [14]. The problem lies in the way many firms measure performance and reward managers. However, there is a striking difference between the economic theory about the firm and the health care organization. The firm adheres to the firm perspective, which is maximizing shareholders wealth by following the net present value rule (choosing those projects with the highest net present value). CEAs in health care usually follow a societal perspective maximizing societal health using the incremental cost per quality-adjusted life year rule.

The societal perspective and the perspective of health care management, which is often accountable for short-run results such as, for example, a balanced yearly budget or is restricted by financial frameworks like, for example, a fixed depreciation period, might well be in conflict. In health care systems where budgetary excesses are sanctioned by a discount in the budget for the following year, achieving the budget becomes so important that those who perceive great pressure to meet the budget may be less inclined to partake of any activity that may increase the uncertainty in their environment, i.e., investing in a new cost-effective technology. For the management of health care organizations, investing in a new cost-effective technology means that this new technology will probably coexist with the inefficient alternative(s) for a considerable time period. Co-existence of alternative technologies leads to increasing inefficiency for the organization as well as for society. The reasoning behind co-existence of alternative technologies is the use of opportunity costs as a measure of costs. For fixed factors of production (in the short run), there is no alternative use. Hence the short-run opportunity cost of using these fixed factors for production is zero. This assumption is only an approximation of what really happens in common medical practice. In many situations, the opportunity cost is not zero, but the lack of alternatives in the short run still means that the opportunity cost is lower in the near term than in the long term. This makes it in the short run less attractive to substitute the new technology for the old one. Obviously production factors are not homogeneous, and scarcity cannot smoothly be compensated with excess capacity elsewhere.

The short run can be considered a time period where at least one production factor is fixed. For infrastructure and capital such as building space or diagnostic devices such as CT (computer tomography) or MRI, the short run might be quite long as financing is determined by a fixed depreciation period of 10-40 years. In general, CEAs assume away 
the fixed-factor problems and therefore look overly optimistic in the sense that inefficiencies caused by coexistence of alternative technologies in the same organization are neglected.

\section{Diseconomies of scale and scope}

A focus on the short run necessitates the inclusion of information about diseconomies of scale and scope. Diseconomies of scale refer to the relationship of average costs with volume of production. For example, one can consider scale economies to the degree that costs change in relation to changes in number of hospital beds or changes in number of diagnostic performances by MRI. Diseconomies of scale arise when marginal costs of production rise, with increasing volume of production, higher than average cost. This may be the result of a variety of factors: returns to scale, behavior of overheads, indivisibility of factors of production, nature of contracts between different stakeholders and the way of organizational governance.

Diseconomies of scope refer to the multipurpose use of capital investments. Diseconomies of scope are conceptually similar to diseconomies of scale. Where diseconomies of scale refer to changes in the output of a single technology, diseconomies of scope refer to changes in the number of different types of technologies. For example, transferring the diagnostics surrounding a certain illness from CT to MRI decreases the multi-purpose use of CT. Capacity of the CT modality is freed, and the MRI modality needs more capacity. In a worse-case scenario, a transition from CT to MRI might cause diseconomies of scope with regard to CT and diseconomies of scale in MRI due to the fact that both CT and MRI production is carried out at levels that are not at the designed optimum capacity with the consequence that unit costs will be higher for both technologies. For a mathematical representation of economies of scale and scope, Kass [6] is referred to. Such diseconomies are not just related to 'high tech' technologies such as expert systems, CT, MRI or PET (positron emission tomography) scan. In general, a CEA considers the production processes of the competing technologies isolated from the organization in which these technologies are embedded. Such diseconomies might also occur in integrated care technologies or clinical practice guidelines such as, for example, structured diabetes care. Such processes, which can be regarded as supply chains, are particularly vulnerable to process indivisibilities as stages in the production process are dependent on each other [15].

In general, the short-run economic obstacles surrounding implementation of cost-effective new technologies might become more important if the rate 'fixed costs to total factor costs' becomes larger.

\section{Diseconomies of learning}

Although the focus of this paper is pre-dominantly on the cost or input site of the production process, the outcome of a new technology's production process might suffer as well in the short run. This might be due to diseconomies of learning. Diseconomies of learning are about the relationship of volume of health care production and quality of health care. During the implementation phase, old and new technology may co-exist. However, most practitioners are less familiar with the new technology than with the old. Economies of learning refer to decreasing average cost, or increasing average effectiveness, as a result of accumulating experience and know-how. Transition from old to new technologies may well cause the opposite effect: increasing average costs, or decreasing average effectiveness, as experience is lacking. It is found that morbidity and mortality is lower in hospital departments, which perform more of a given procedure. This result has been found for a wide variety of different procedures, time periods, and locations [16]. Shifting from technology might well cause an increase in morbidity and mortality rates or more general cause medical quality of care to drop temporarily.

\section{Challenges for economic evaluation of new technologies and clinical practice guidelines}

Partly responsible for stagnation of implementation of efficient technologies and the co-existence of alternative efficient and inefficient technologies in health care is the lack of focus on short-run efficiency and the health care perspective. It is important to link knowledge about costeffectiveness to potential short-run economic obstacles. This can be done in its simplest form by, for example, presenting a rate 'fixed costs to total factor costs' of a new technology and the already existing alternatives together with the cost-effectiveness information. Doing so might speed up adoption of a cost-effective technology as it provides insight into potential hurdles or barriers to implementation that might be (partially) overcome by specific strategies. One can think of, for example, implementation strategies dealing with operational/financial characteristics (for example, adapt capacity planning or accounting for time till re-investment) or strategies that actively search for alternative use of fixed production factors of inefficient technologies and thereby increase the opportunity costs of these 'freed' production factors. Consequently, CEAs should be complemented by analyses that deal with the cost of shifting or retiring fixed factors of production. Including such strategies in the implementation of new technologies might minimize the co-existence of 
competing technologies and ultimately result in a more efficient health care.

A step further would be if the aim of economic evaluation of innovations in health care adds to the CEA-based research question another research question, namely: "what is the additional value of technology $\mathrm{X}$ for organization $\mathrm{W}$ when $\mathrm{X}$ is implemented in common practice?" The last question explicitly deals with the investment necessary to embed the technology in the organization, how this technology interferes with existing technologies in the organization and consequently whether diseconomies of scale, scope, and learning occur on the short run. However, performing a CEA does not result in an answer to such a research question. CEAs are often performed alongside clinical trials, meaning they share the same methodology as clinical trials. Such trials have, in general, experimental designs, which differ from each other in the degree of experimental control. The higher the level of control, the more robust the evidence supporting a causal relationship. Such a design has a very narrow scope focusing on a homogeneous patient population and alternative technologies intervening in this specific patient population only (disregarding multipurpose use of technologies). Obviously such a design is not suitable to answer the question of what the impact of a technology is on the health care provider as a whole, both in the short and long run. Presently in the Netherlands guidelines with regard to pharmaco-economic evaluation of expensive inpatient pharmaceuticals are being developed. These guidelines aim at investigating common practice efficiency of a technology. A focus on common practice necessitates parting from experimental designs, moving towards naturalistic designs with less control and consequently more heterogeneity in the population. Such a development makes it possible to consider the impact of potentially cost-effective technologies on the production process related to a more heterogeneous group of patients and how such technologies interfere with existing production processes and budgetary constraints in the organization. This approach provides information on both long- and short-run efficiency of a new technology from the perspective of an organization or health care provider. Based on such knowledge one can develop implementation strategies to increase the level and time of adoption. This information, together with CEA information, supports decision-making on the implementation of new technologies in a more useful way.

Open Access This article is distributed under the terms of the Creative Commons Attribution Noncommercial License which permits any noncommercial use, distribution, and reproduction in any medium, provided the original author(s) and source are credited.

\section{References}

1. Aletras, A.: Comparison of hospital scale effects in short run, long run cost functions. Health Econ. 8, 521-530 (1999)

2. Elbasha, E.H., Messonnier, M.L.: Cost-effectiveness analysis and health care resource allocation: decision rules under variable returns to scale. Health Econ. 13, 21-35 (2004)

3. Vitaliano, D., Toren M.: Cost and efficiency in nursing homes: a stochastic frontier approach. J. Health Econ. 13, 281-300 (1994)

4. Gertler, P., Walman D.: Quality-adjusted cost functions and policy evaluation in nursing home industry. J. Polit. Econ. 100, 1232-1256 (1992)

5. Dor, A.: The costs of medicare patients in nursing homes in the United States : a multiple output anapysis. J. Health Econ. 8, 253-270 (1989)

6. Kass, D.: Economies of scale, scope in the provision of home health services. J. Health Econ. 6, 129-146 (1987)

7. Adang, E., Voordijk, L., Wilt van der, G.J., Ament, A.: Costeffectiveness analysis in relation to budgetary constraints and reallocative restrictions. Health Policy 74, 146-156 (2005)

8. Roberts, R., Frutos, P., Ciavarella, G.: The distribution of variable vs fixed costs of hospital care. JAMA 281, 644-649 (1999)

9. Hartman, M., Prins, M., Swinkels, O.Q.J., Severens, J.L., Boo de T., Wilt van der G.J., et al.: Cost-effectiveness analysis of a psoriasis care instruction programme with dithranol compared with UVB phototherapy and inpatient dithranol treatment. Br. J. Dermatol. 147, 538-544 (2002)

10. Drummond, M.F., Sculpher, M.J., Torrance, G.W., O’Brien, B., Stoddart G.L.: Methods for the economic evaluation of health care programmes. Oxford University Press, Oxford (2005)

11. Gold, M.R., Siegel, J.E., Russel, L.B., et al.: Cost-effectiveness in health and medicine. Oxford University Press, NewYork (1996)

12. Katz, M.L., Rosen, H.S.: Microeconomics. Irwin, Boston (1991)

13. Copeland, T.E., Weston, J.F.: Financial theory and corporate policy. Addison-Wesley, New York (1988)

14. Jensen, M., Meckling, W.: Theory of the firm: managerial behavior, agency costs and ownershipstructure. J. Financ. Econ. 3, 305-360 (1976)

15. Tone, K., Sahoo, B.K.: Scale, indivisibilities and production function in data envelopment analysis. Int. J. Prod. Econ. 84, 165-192 (2003)

16. Birkmeyer, J.D., et al.: Hospital volume and surgical mortality in the United States. N. Engl. J. Med. 346(15), 1128-1137 (2002) 